\title{
DESENVOLVIMENTO RURAL, ESTADO E SOCIEDADE: as políticas de modernização, colonização e reforma agrária no Brasil
}

\author{
Luiz Antonio Cabello Norder
}

A questão agrária precisa ser compreendida como um processo contínuo, como parte integrante e necessária do desenvolvimento econômico não apenas de sociedades "atrasadas", mas também de qualquer sociedade "avançada". Não se trata de um problema restrito ao período de formação das sociedades capitalistas, ou da dissolução dos obstáculos que levariam ao desenvolvimento do capitalismo, nem de uma suposta transição para o socialismo. Em cada época, em cada região, há uma articulação entre a questão agrária e o conjunto de transformações nas relações sociais e organizações políticas. A formação do mercado de trabalho, a distribuição de renda e os níveis de consumo das classes trabalhadoras em cada país decorrem, em grande medida, da forma como é conduzida historicamente a distribuição do espaço fundiário.

Nesse sentido, não chega a ser surpreendente a atualidade da questão agrária no Brasil e em muitos outros países, incluídos os chamados desenvolvidos. Entretanto, em alguns países, a reforma agrária tem objetivos exatamente opostos aos da reforma agrária "distributivista" que está em debate no Brasil. Isso significa que, enquanto em alguns países a reforma agrária visa diminuir um generalizado minifundismo, no Brasil procura-se retirar grandes propriedades rurais do estado de desocupação e improdutividade. Esta é uma particularidade brasileira, compartilhada com vários países latino-americanos, principalmente Colômbia, Peru e México.

O tema da reforma agrária ganhou grande destaque político no Brasil nesta década de 90, particularmente a partir de 1995. Episódios de violência física, associados às recorrentes notícias de "invasões de propriedades", passaram a despertar o interesse de grande parcela da sociedade para o tema. Desde os anos 50, tem sido intenso o debate 
sobre a questão agrária brasileira. A bandeira da reforma agrária conheceu diferentes significados históricos: a reforma agrária que se discutia nos anos 60 não é a mesma dos anos 70; nos anos 90 ela tem ainda outras particularidades. É uma questão em permanente transformação, em sintonia com as alterações nas relações sociais no campo e nos centros urbanos e industriais.

Nos anos 50 e 60 ganharam enorme destaque as Ligas Camponesas, principalmente na região Nordeste do país, e outros movimentos sociais bastante articulados e combativos, como o Movimento dos Agricultores Sem-Terra (MASTER), no Sul do Brasil. ${ }^{1}$ A reforma agrária tornou-se desde então uma questão altamente polêmica, um tema central na agenda política brasileira, sobretudo após a revolução socialista em Cuba, em 1959. Naquela conjuntura, a idéia de reforma agrária passou a ser associada ideologicamente a um certo projeto de desenvolvimento econômico, o projeto socialista, que vinha sendo implementado no leste europeu, e que havia renovado suas forças no Brasil após a revolução cubana.

A suposição de que a reforma agrária era um projeto preponderantemente comunista reduziu o leque de discussões e tornou a questão bastante estigmatizada. As primeiras iniciativas em favor da reforma agrária, tomadas nos anos 60 pelo então presidente João Goulart, acabaram por servir como um dos principais pretextos para o golpe militar em 1964. Estabeleceu-se então um regime militar, um regime autoritário, repressivo. Os militares que tomaram o poder tinham um determinado projeto de desenvolvimento para a sociedade, um projeto político presente não apenas entre aqueles que passaram a controlar o Estado, mas um projeto que atendia aos interesses econômicos de determinados segmentos da sociedade. E qual era esse projeto político? Quais eram as mudanças agrárias pretendidas e implementadas pelo regime militar?

\section{A POLÍTICA AGRÁRIA NOS ANOS DE CHUMBO}

A primeira medida tomada durante o regime militar foi justamente deixar claros os limites para a atuação dos movimentos sociais, partidários e sindicais: um aniquilamento das liberdades civis e políticas; uma segunda importante característica deste projeto político e econômico vigente no regime militar foi a substituição da proposta de reforma 
agrária defendida pelas organizações populares, pela chamada "colonização dirigida" na região amazônica; um terceiro elemento fundamental neste "modelo" de desenvolvimento agrário foi o acentuado incentivo governamental à modernização tecnológica de grandes empreendimentos agropecuários em bases propriamente capitalistas.

O Estado passou a atuar de uma nova forma, passou a desempenhar um papel central e decisivo no desenvolvimento do capitalismo no meio rural brasileiro. Alguns autores chegam a afirmar que o Estado havia adquirido naquela época uma "fúria regulatória", uma "fúria intervencionista", que se traduz naquilo que se conhece hoje como a "modernização conservadora". Tal política de incentivos era composta por créditos subsidiados, seguro agrícola (Proagro), pesquisa (Embrapa), assistência técnica (Emater), garantia de preços mínimos, estoques reguladores, programas de abastecimento interno (Cibrazem, Cobal, Ceasa, Rede Somar), gerenciamento de taxas de câmbio em níveis favoráveis às exportações, isenções e rebates, além de programas específicos para a produção de álcool, papel e celulose, soja e outros produtos. (Belik, 1997)

A idéia de modernização não se prendia apenas à aplicação na agricultura de novas tecnologias químicas e mecânicas de origem industrial. Tratava-se da transformação de fazendas tradicionais em modernos empreendimentos capitalistas, com uma significativa redefinição das relações sociais. As fazendas de café, por exemplo, tinham em seu interior trabalhadores que eram também moradores, ou seja, uma mão-de-obra fixa no interior das fazendas, onde se combinavam atividades nos cafezais com atividades de subsistência. (Stolcke, 1994).

Buscava-se a transformação dessas fazendas em grandes empreendimentos comerciais, com o uso de trabalhadores assalariados, temporários e permanentes, preferencialmente sem residência no interior da propriedade. Predominavam determinadas relações sociais, determinados conflitos políticos, determinadas técnicas produtivas, cuja desestruturação abriria espaço às modernas empresas agropecuárias, tecnificadas, integradas no mercado internacional, consumindo insumos industriais e operando com base nos contratos (formais e informais) de trabalho assalariado. Isso alterava completamente as condições de vida e de trabalho da população rural. Inaugurava-se um nova fase no processo de produção capitalista de mercadorias agropecuárias no Brasil. 
O programa de desenvolvimento agropecuário do regime militar foi sistematicamente discriminatório. Para se ter uma idéia, 60\% do crédito agrícola voltou-se para cinco produtos: soja, café, algodão, açúcar e milho; $40 \%$ do crédito beneficiou a apenas $1 \%$ dos produtores, que desta forma puderam empregar $3 \%$ da força de trabalho na agricultura. Registram-se além disso casos de financiamento da ordem de US\$900 milhões distribuídos entre 355 produtores (uma média de US\$ 2,5 milhões por empreendimento). Havia uma notável "megalomania agrária": a promoção a qualquer custo de grandes empreendimentos agroindustriais. A contrapartida foi seu caráter socialmente excludente, em um ambiente de repressão política. Dessa forma, promoveu-se o capitalismo agrário no Brasil, nesse contexto político específico, com este conjunto de políticas governamentais. (Grindle, 1986)

Os institutos de reforma agrária no período militar dedicavamse a administrar de forma bastante ineficiente, se não de forma corrupta, os projetos de colonização na região amazônica. O eixo dado pela rodovia Transamazônica que liga o Estado de Rondônia e o Estado do Pará foi o norteador dos deslocamentos da população rural. Pretendiase transferir os conflitos rurais, transferir a questão da reforma agrária, para essa região. Os resultados foram catastróficos. Primeiro, porque esses projetos eram ambientalmente insustentáveis: a prática da agricultura e da pecuária esgotavam os recursos naturais em poucos anos. Havia ainda a falta de uma infra-estrutura social mínima para esses projetos (transporte, saúde, educação, eletrificação etc.). E nas regiões para além dessas áreas ocupadas pelos colonos que saíram do Centro-Sul e do Nordeste houve a concessão de grandes lotes de terras. A colonização da Amazônia tinha este dualismo, e acabou se configurando como mais um processo de concentração da propriedade fundiária. $^{2}$

É importante ressaltar outra característica dos projetos de colonização: a existência de diversos massacres de trabalhadores ocorridos por toda a região amazônica, muitos deles ainda hoje pouco conhecidos. Não é mera coincidência que os massacres de 1995 e 1996, respectivamente, em Corumbiara (Rondônia) e Eldorado dos Carajás (Pará), tenham ocorrido justamente nas duas extremidades da rodovia Transamazônica. Essa região tem ainda hoje a maior incidência de violência física ilegítima praticada por grupos pára-militares: assassinatos, torturas, perseguições, escravidão. 
Portanto, durante o regime militar, houve uma modernização da produção agropecuária que mudou radicalmente as relações de trabalho, as relações entre agricultura e indústria, e entre campo e cidade; mas essas mudanças foram, primeiramente, limitadas a alguns produtos, circunscritas a certas regiões, direcionadas a um determinado tipo de produtor; mesmo assim, desencadearam um grande movimento migratório e um acelerado êxodo rural.

Verificaram-se fluxos migratórios significativos, em direção à região amazônica (é certo que grande parte dessa população veio a abandonar os projetos de colonização para regressar não raro à sua região de origem, e que uma parte dela passou a integrar o Movimento dos Trabalhadores Rurais Sem-Terra) e também em direção aos principais centros metropolitanos e cidades de porte regional. Por outro lado, enormes áreas de terra permaneceram e ainda hoje permanecem improdutivas ou subutilizadas, enquanto a grande maioria dos pequenos municípios brasileiros, ao longo desse processo, entrou em completa decadência: decadência populacional, econômica, comercial. ${ }^{3}$

\section{A REEMERGÊNCIA DOS MOVIMENTOS SOCIAIS NO CAMPO}

Esse programa de desenvolvimento agrário entrou em colapso a partir de meados dos anos 80 . As conseqüências das políticas agrícolas de modernização excludente, discriminatória, concentradora de renda e fundamentada em subsídios governamentais, direcionados às grandes empresas capitalistas, ao lado do esgotamento da colonização dirigida na região amazônica (o MST desde seu início vem criticando a colonização dirigida na Amazônia) e das contradições geradas pela urbanização mais acelerada que o crescimento econômico, gerando uma enorme precariedade nas aglomerações urbanas, estão entre os fatores que impulsionaram a formação dos movimentos sociais que resgataram a bandeira da reforma agrária durante a transição para a democracia, nos anos 80. Houve uma reorganização do sindicalismo, a volta ao sistema pluripartidário e a articulação de inúmeros movimentos sociais rurais e urbanos.

Nesse mesmo período, houve uma redução naquela "fúria intervencionista" para o desenvolvimento do capitalismo agrário no Brasil. A luta pela redemocratização do Brasil foi simultaneamente uma 
luta contra a repressão política, pela reconquista das liberdades civis, sindicais e partidárias, e também uma luta contra aquele projeto excludente de desenvolvimento rural. Na primeira metade dos anos 80 , nós tivemos o reaparecimento das organizações populares de luta pela reforma agrária, um resgate dessa alternativa política, e um combate aos privilégios em torno das políticas agrícolas, ou seja, a oposição aos subsídios, incentivos e programas especiais voltados para a promoção de setores capitalistas de produção agropecuária e agroindustrial. Existe uma aproximação importante entre essas duas frentes de disputa política. Atualmente, diversos autores falam da importância de realizar uma "liberalização" dessa produção patronal na agricultura, de efetuar uma desativação da intervenção protetora do complexo agroindustrial brasileiro.

E de fato, principalmente nos anos 90 , verifica-se uma passagem daquela fúria regulatória estatal para uma espécie de auto-regulação corporativa, uma regulação setorial, uma reorganização dos canais de produção e circulação de mercadorias. (Belik, 1997) Vários segmentos de produção patronal na agropecuária brasileira ficaram enfraquecidos com essas alterações, e isso ajuda a explicar o aumento do desemprego no campo, o que, por sua vez, veio a ampliar a luta pela reforma agrária. Ao lado desse enfraquecimento do setor agroindustrial exportador, seja devido à redução do apoio do Estado a essas atividades, seja devido à queda nos preços das principais mercadorias (commodities) colocadas pelo Brasi] no mercado internacional, ${ }^{4}$ existem outros fatores que também contribuíram para o ressurgimento dos movimentos sociais no campo, entre eles a precarização das condições de vida nas cidades ${ }^{5}$ e o aumento nos níveis de desemprego em praticamente todo o país.

Houve ainda nos anos 90 a consolidação de uma linha de ação nos movimentos sociais e um aumento do apoio da sociedade civil urbana para o Movimento Sem-Terra. Quanto às estratégias políticas dos movimentos sociais, a organização do MST inclui uma diversificada ação política com dimensão nacional, mas em articulação com formas localizadas de ação direta. Formara-se assim uma instituição de representação social e política dos trabalhadores rurais sem-terra em geral, ao mesmo tempo em que são promovidas ações locais específicas, com grupos sociais específicos. (Petras, 1997) A história do MST é dada pela construção desta organização política nacional e, simultaneamente, pela conquista de áreas e políticas públicas para a implementação de assentamentos rurais. 
E como é essa "ação local" do Movimento Sem-Terra? A iniciativa de participar da luta pela terra vem dos próprios trabalhadores. $\mathrm{O}$ MST organiza um grupo interessado na disputa fundiária. Em seguida, há a identificação da área que este grupo vai disputar, ou seja, uma delimitação territorial e social da luta pela reforma agrária, o que define quem são as pessoas que vão disputar qual área específica. Monta-se um acampamento nas imediações e inicia-se a negociação do acesso a esta área com o governo. A seleção das áreas passa pela preexistência de laudos oficiais de improdutividade, pela fragilidade dos títulos de propriedade, pela ocupação irregular de áreas públicas por grandes fazendeiros, a existência de dívidas com o sistema financeiro estatal ou inadimplência nas políticas agrícolas, enfim, uma série de critérios que podem facilitar a ocupação definitiva dessas áreas pelos trabalhadores. No caso de as negociações emperrarem, faz-se uma ocupação.

O MST tem uma deliberação geral de não se contrapor à violência policial. No caso da ocupação de uma fazenda, a diretriz principal é que, diante da chegada de uma liminar de reintegração de posse, se desocupe a propriedade, voltando ao acampamento e reiniciando as negociações com o governo. Diante da continuidade dos obstáculos nas negociações, procede-se a uma nova ocupação: ocupa-desocupareocupa. Todavia, as decisões são tomadas localmente, de forma descentralizada. Em alguns casos ocorrem saques, resistências às desocupações, ocupação de prédios públicos etc. A violenta reação policial contra as "invasões" recebe, muitas vezes, suporte de organizações pára-militares ligadas aos fazendeiros da região. Ecoa-se, nestas horas, as suposições acerca da participação da União Democrática Ruralista (UDR) em tais episódios. ${ }^{6}$

É justamente através desse processo que os assentamentos foram conquistados pelo MST. Como decorrência dessa estratégia, a reforma agrária hoje no Brasil tornou-se um processo de reforma agrária "parcial": a luta pela reforma agrária não é uma luta indiscriminada contra o latifúndio, uma luta genérica, abstrata. É uma luta localizada, uma luta concreta, imediata. Isso estimula a adesão dos trabalhadores à organização. Estima-se hoje que haja no Brasil algo em torno de 300 a 400 mil famílias assentadas, ${ }^{7}$ o que representa o atendimento de uma parcela muito pequena da população rural sem terra. ${ }^{8} \mathrm{E}$ "parcial" porque não chegou a alterar o quadro de predominância da grande produção agropecuária e agroindustrial capitalista. 


\section{A CONSTRUÇÃO DOS ASSENTAMENTOS RURAIS}

Além deste alcance político e populacional de certa forma limitado, não há uma política de desenvolvimento rural consistente e adequada para os programas de reforma agrária, bem como para todo o setor agropecuário familiar brasileiro. Os assentamentos rurais enfrentam uma enorme precariedade e a população assentada e acampada, em geral, é pobre e analfabeta.

É claro que é um processo extremamente complicado o de transformar esta população pobre e analfabeta em "produtores agropecuários eficientes e integrados no sistema de mercado", como consta em documentos oficiais recentes, até mesmo devido às relações sociais experimentadas anteriormente, de subordinação à lógica de acumulação de capitais nas grandes propriedades via trabalho assalariado. As dificuldades passam pelo problema educacional. Dentre as $300 \mathrm{mil}$ famílias assentadas em diferentes programas do govemo federal, com relação à situação do titular jurídico do lote, $30 \%$ são analfabetos; outros $50 \%$ são semi-alfabetizados ou pessoas que cursaram até três anos de ensino formal; $92 \%$ do total de titulares de lotes nos assentamentos e programas de colonização têm no máximo quatro anos de ensino formal; $64 \%$ desta população assentada não têm qualquer outra habilidade profissional senão a de agricultor/trabalhador rural.

Essa população resiste nos assentamentos em uma situação de enorme precariedade. Basta dizer que apenas $20 \%$ dos lotes contam com eletricidade; que a irrigação atinge apenas de 3 a $7 \%$ dos lotes; que no Nordeste, a região que mais necessita de irrigação, apenas 4 ou $5 \%$ dos lotes estão irrigados. As condições gerais nas regiões Norte e Nordeste são as mais difíceis: tais famílias vivem em assentamentos sem eletricidade durante vários anos; $75 \%$ das famílias não têm fogão a gás; $93 \%$ não têm geladeira; e $90 \%$ não têm televisão. Nas regiões Sudeste e Sul as condições são um pouco melhores. (Schimidt, Marinho e Rosa, 1998)

Ainda assim, na maioria dos casos, o índice de evasões é bastante baixo. Uma pesquisa realizada pela FAO, em convênio com o INCRA, mostrou que a média nacional de evasão dos projetos seria de aproximadamente $20 \%$. Entretanto, na região Norte, onde se localiza grande parte das famílias assentadas no Brasil, o índice de evasões seria 
de 40 a $50 \%$, o que estaria elevando a média nacional. É onde existe a malária, e onde não há escolas, hospitais, eletrificação, canais de comercialização etc. Nas regiões Nordeste e Centro-Sul, permanecem anualmente nos assentamentos cerca de $95 \%$ das famílias. ${ }^{9}$ Existem vários assentamentos nos estados de São Paulo, Paraná, Santa Catarina e Rio Grande do Sul onde o índice de permanência é da ordem de $98 \%$ ao ano. O mesmo ocorre em diversos assentamentos nos estados do Nordeste e do Centro-Oeste. A ideologia em torno da "venda de lotes" baseia-se muito naqueles projetos de colonização onde as pessoas não dispunham de condições mínimas de sobrevivência. E talvez a melhor coisa que essas pessoas poderiam fazer, naquelas condições, era tentar vender seu lote de terra e procurar, com tal recurso, fazer alguma outra coisa, em algum outro lugar.

Esse elevado índice de permanência nas regiões de maior densidade demográfica ocorre não apenas porque as alternativas de emprego e urbanização são desfavoráveis. Ainda que as famílias não queiram se aventurar em uma saída dos assentamentos, elas ali permanecem também porque há uma reconstrução da vida familiar a partir praticamente do nada. As familias buscam construir organizações comunitárias para reorganizar seu cotidiano e se restabelecer na produção e na conquista de algumas políticas sociais.

Com relação à habitação, outro componente central na reprodução da força de trabalho, o governo federal vinha destinando aos assentamentos uma verba de $\mathrm{R} \$ 2$ mil por família, o que representaria hoje cerca de quinze salários mínimos, ou aproximadamente mil dólares. Recentemente, este valor foi reduzido para $\mathrm{R} \$ 1.200,00$, no âmbito da "nova reforma agrária". As famílias precisam construir suas casas sob o regime ajuda-mútua, troca de dias de trabalho ou mutirão - uma alternativa de ocupação da força de trabalho nos assentamentos. Aquelas famílias que possuíam algum recurso antes do assentamento prosperam muito mais rapidamente, seja no encaminhamento da produção, seja na solução da questão habitacional e educacional.

É preciso reconhecer que o processo de produção agropecuária nos assentamentos não segue exatamente a mesma lógica de uma moderna empresa agropecuária. ${ }^{10}$ Mesmo assim, a produção de mercadorias agropecuárias é indispensável, principalmente pelo fato de que esta população não conta com outras alternativas econômicas e profissionais. Dentro destas áreas, ocupadas em geral por uma população pobre, a 
reprodução da força de trabalho é realizada em estreita associação com essa produção comercial. É uma produção de mercadorias realizada em um contexto de relações sociais extremamente adverso, contra o qual os assentados procuram mobilizar-se permanentemente.

Algumas pesquisas mostram que muitas das famílias assentadas estão hoje fora de uma situação de pobreza, considerando os mesmos parâmetros que classificam de 30 a $40 \%$ do total da população brasileira nas situações de miséria e pobreza. ${ }^{11}$ A geração de renda monetária a partir da produção agropecuária tem sido a principal fonte de recursos para muitos assentamentos rurais. Mas a constituição do processo produtivo nos assentamentos, bem como em qualquer atividade econômica, é também, numa acepção mais ampla, uma luta política, uma luta social. Existem inúmeras estratégias sociais já lançadas, em cada localidade, de reelaboração do processo produtivo, de desconstrução do chamado "pacote tecnológico moderno", com o uso seletivo de tecnologias, a criação de associações e cooperativas, a busca pela produção de novas mercadorias, a inserção em nichos de mercado, a combinação dessas atividades agropecuárias com ocupações nãoagrícolas fora do lote - o que resulta em um cenário socioeconômico profundamente heterogêneo. ${ }^{12}$

Além disso, em uma considerável parte das famílias que se propõem a participar dos programas de reforma agrária, ou ainda entre os agricultores familiares que procuram fortalecer sua produção agropecuária, há uma combinação entre a integração nos sistemas de produção comercial com tradicionais práticas camponesas, como a produção de alimentos para o consumo familiar, a prática de mutirões e ajuda mútua em substituição ao pagamento de assalariados, e outras atividades - e não apenas entre as famílias mais próximas da situação de pobreza. Assim que uma família adquire um lote de terra, após a trajetória de lutas políticas nos acampamentos, há uma imediata reconstituição de práticas camponesas, que contribuem decisivamente para se atingir a segurança alimentar no meio rural: é a horta, o pomar, a criação de pequenos animais, os pequenos roçados. Essa produção para o consumo doméstico, como já o mostrava Queiroz (1973), Cândido (1964) e Brandão (1981), entre outros autores, é quase sempre apenas parcial. Isso é complementado por um volume, crescente talvez, de produtos adquiridos no mercado. Esse tipo de atividade é combinado de inúmeras formas com a produção de mercadorias e ocupações fora do lote. (Garcia Jr., 1990; 1994) 
É justamente por essa associação entre a produção de mercadorias agropecuárias e seu processamento industrial, fonte indispensável de recursos monetários, com as práticas de reprodução da força de trabalho via produção de valores de uso, principalmente no que se refere à alimentação e habitação, que se encontram os limites e as potencialidades dos assentamentos rurais. As atuais políticas de desenvolvimento rural para a agricultura familiar e para os assentamentos rurais são ainda inadequadas e insuficientes. Por outro lado, os assentados evidenciam que, apesar disso, existe um enorme potencial para a geração de empregos, promoção da segurança alimentar, atenuação, pelo menos, do problema habitacional e fortalecimento da construção da cidadania.

\section{NOTAS}

1 Ver Medeiros (1989).

2 Ver Tavares dos Santos (1993); Bergamasco \& Norder (1996).

3 Sobre a dinâmica demográfica e a situação de pequenos municípios, ver Faria (1991).

4 Houve, ao longo da década de 90 , uma redução média de $50 \%$ no preço das principais commodities produzidas no Brasil: algodão, arroz, café, açúcar, cebola, feijão, laranja, milho e soja. "O resultado foi uma brutal queda na rentabilidade das atividades agropecuárias tradicionais (...) [e uma] redução nos valores dos principais ativos agrícolas, especialmente a terra, que (...) tem apresentado queda constante nos seus preços a partir de 1995". (Graziano da Silva, 1997)

5 Chegou a ser divulgada a informação de que a cidade de São Paulo estaria nos anos 90 com cerca de $25 \%$ de sua população morando em favelas e cortiços; e que no Rio de Janeiro, 34\% das pessoas estariam morando em tais condições. (Floresta, 1999).

- Uma detalhada abordagem jornalística sobre a violência da ação policial (e pára-militar) no Estado do Paraná em 1999 foi realizada por José Arbex Jr. e Marco Frenetti, publicada na revista Caros Amigos, n.27, de junho de 1999. Conforme a reportagem, as ações da polícia teriam o objetivo de destruir a organização do MST no Paraná, e estariam adquirindo um "grau inédito de organização, método e abrangência (...) as estratégias utilizadas são de criminalização, caça às lideranças e uso do terror nos despejos".

7 As estatísticas sobre os assentamentos rurais no Brasil são muito pouco confiáveis e inespecíficas - em grande medida são confundidos os programas de reforma agrária com os programas de colonização, programas de regularização fundiária, programas de ocupação de terras públicas e outros. Vale ressaltar que em 1999 o INCRA vem trabalhando com a estimativa de aproximadamente 414 mil famílias "assentadas".

8 No MST, calcula-se que o público a ser eventualmente beneficiado pela reforma agrária seria de 2 a 3 milhões de famílias.

9 Para maiores detalhes, ver Guanziroli (1994).

${ }^{10}$ As análises sobre as "especificidades" da organização da produção agropecuária em bases familiares partem das formulações teóricas de Chayanov (1985).

"Para uma discussão metodológica e análise empírica sobre a geração de renda 
agropecuária, pluriatividade, pobreza e não-pobreza e alimentação em assentamentos, ver Norder (1998).

${ }^{12}$ No período militar, a concessão das políticas de incentivo era condicionada ao uso de determinados insumos e equipamentos. A expressão "pacote tecnológico" tinha, portanto, um fundamento objetivo. Atualmente, torna-se necessário observar como os agricultores "desconstroem" este "pacote", através do uso seletivo e adaptado de recursos tecnológicos. Isso repercute, por exemplo, de forma diferenciada no montante de força de trabalho utilizada, nas relações sociais, produtividade e rentabilidade de cada cultura.

\section{REFERÊNCIAS BIBLIOGRÁFICAS}

ARBEX JR., José \& FRENETTI, Marco. Horror no Paraná. Caros Amigos, n.27, p.2638, jun. de 1999.

BELIK, W. Changing patterns of State intervention in the brazilian agro-industrial complex. Sociologia Ruralis, v.37, n.3, 1997. p.405-424.

BERGAMASCO, S. \& NORDER, L. O que são assentamentos rurais. São Paulo: Brasiliense, 1996. (Col. Primeiros Passos)

BRANDÃO, C.R. Plantar, colher, comer. Rio de Janeiro: Graal, 1981.

CÂNDIDO, A. Os parceiros do rio Bonito. Rio de Janeiro: José Olympio, 1964.

CHAYANOV, A.V. La unidad economica campesina. Buenos Aires: Nueva Visión, 1985.

FARIA, V.E. Cinquenta anos de urbanização no Brasil: tendências e perspectivas. Novos Estudos Cebrap, n.29, p.98-119, mar. 1991.

FLORESTA, C. Favelas vão abrigar 1 bilhão de pessoas. Folha de S. Paulo, 2 mai. 1999. cad.1, p.12.

GARCIA JR., A.R. Sul: o caminho do roçado. Rio de Janeiro/Brasília: Marco Zero/ CNPq, 1990.

Geração de rendas, sua distribuição e trajetórias diferenciais em assentamentos de reforma agrária do Brasil (1985-1989). In: ROMEIRO, A. et al. (orgs.) Reforma agrária: produção, emprego e renda. Petrópolis: Vozes, 1994.

GRINDLE, M.S. State and countryside: development policy and agrarian politics in Latin America. Baltimore: Johns Hopkins University Press, 1986.

GUANZIROLI, C. (coord.) Principais indicadores sócio-econômicos dos assentamentos de reforma agrária. In: : ROMEIRO, A. et al. (orgs.) Reforma agrária: produção, emprego e renda. Petrópolis: Vozes, 1994. p.30-53.

Diretrizes de política agrária e desenvolvimento sustentável. Brasília: FAO/ INCRA, mar. 1995

MEDEIROS, L.S. História dos movimentos sociais no campo. Rio de Janeiro: FASE, 1989.

NORDER, L.A. A construção da segurança alimentar em assentamentos rurais: questões, contextos e métodos. Cadernos de Debates: Revista do Núcleo de Estudos e Pesquisas em Alimentação, v.VI, p.40-58, Campinas: NEPA/Unicamp, 1998. 
PETRAS, J. Os camponeses: uma nova força revolucionária na América Latina. In: STÉDILE, J.P. (org.) A reforma agrária e a luta do MST. Petrópolis: Vozes, 1997. p.271-177.

QUEIROZ, M.I.P. Bairros nurais paulistas: a dinâmica bairro rural-cidade. São Paulo: Livraria Duas Cidades, 1973.

SCHMIDT, B.V.; MARINHO, D.N., ROSA, S.C. Os assentamentos de reforma agrária no Brasil. Brasília: Editora Universidade de Brasília, 1998.

STOLCKE, V. A família que não é sagrada: sistemas de trabalho e estrutura familiar: o caso das fazendas de café em São Paulo. In: ARANTES, A.A. et al. (orgs.) Colcha de retalhos: estudos sobre a família no Brasil. 3.ed. Campinas: Ed. Unicamp, 1994. p.61-114.

TAVARES DOS SANTOS, J.V. Matuchos: exclusão e luta: do Sul para a Amazônia. Petrópolis: Vozes, 1993.

\section{RESUMO}

Este texto faz um balanço das políticas agrárias e agrícolas governamentais dos últimos 40 anos, com destaque para as bases sociopolíticas do processo de modernização agropecuária e sua articulação com a formulação de programas de ocupação de áreas amazônicas durante o regime militar. Apresenta ainda uma avaliação da transição para a democracia a partir do final dos anos 70 e o questionamento das políticas de desenvolvimento rural então vigentes. Os avanços e limites na implementação dos assentamentos rurais nos anos 80 e 90 são interpretados enquanto expressão de uma nova contradição na relação entre Estado e sociedade civil no Brasil.

Palavras-chave: modernização agropecuária; colonização dirigida; assentamentos rurais; políticas agrárias.

\section{ABSTRACT}

This article presents an overview on the governmental land and agricultural policies in the last 40 years, focusing on the socio-political basis of the agricultural modernization and its articulation with the colonization programs in the Amazon region during the authoritarian regimen. It also presents an assessment about the transition to the representative democracy, which started in the end of the 70's, and analyses the questions concerning the rural development at that time. The advances and limits on the implementation of rural settlements of land reform in the 80 's and 90 's are interpreted as expression of a new contradiction in the relations between state and civil society.

Key words: agricuitural modernization; colonization in Amazon region; rural settlements; land policies.

Luiz Antonio Cabello Norder é professor de Sociologia do Departamento de Ciências Sociais da UEL. 